\title{
Comparative Study between Shortened versus Standard Protocols of Postpartum Magnesium Sulphate Regimen in the Treatment of Eclampsia
}

\author{
Nermeen Mohamed Hefila*, Tamer Mamdouh Abdeldayem \\ Department of Obstetrics and Gynecology, Faculty of Medicine, Alexandria University, Alexandria, Egypt \\ Email: *nermeenptsbasem81@gmail.com
}

How to cite this paper: Hefila, N.M. and Abdeldayem, T.M. (2021) Comparative Study between Shortened versus Standard Protocols of Postpartum Magnesium Sulphate Regimen in the Treatment of Eclampsia. Open Journal of Obstetrics and Gynecology, 11, 935-939. https://doi.org/10.4236/ojog.2021.118089

Received: May 2, 2021

Accepted: July 30, 2021

Published: August 3, 2021

Copyright (อ 2021 by author(s) and Scientific Research Publishing Inc. This work is licensed under the Creative Commons Attribution International License (CC BY 4.0).

http://creativecommons.org/licenses/by/4.0/ (c) (i) Open Access

\begin{abstract}
Eclampsia is one of the most sever, life-threatening diseases occurred in pregnancy, $\mathrm{MgSO}_{4}$ is the best drug used for its treatment. In this study, the comparison between shortened regimen of $\mathrm{MgSO}_{4}$ versus standard Zuspan course in controlling eclampsia was done. This study performed along one year (July 2019-July 2020) at El Shatby Maternity University Hospital, 40 eclamptic patients presenting at the emergency unit were randomized. Group A received the standard Zuspan regimen of magnesium sulphate and group $B$ received short course in which the patients received only two doses of intravenous magnesium sulphate four hours apart postpartal. Results: The maternal outcomes regarding recurrence of the fits were compared. The maternal complications and postpartal fits were the same in both groups. The dose of $\mathrm{MgSO}_{4}$ in the shortened group was decreased by $40 \%$ in $42.5 \%$ of the cases. Conclusions: The shortened course of $\mathrm{MgSO}_{4}$ postpartal is the same as the standard regimen in the controlling eclampsia.
\end{abstract}

Keywords

$\mathrm{MgSO}_{4}$, Eclampsia, $\mathrm{MgSO}_{4}$ Protocols

\section{Introduction}

Eclampsia is known as grand mal seizure activity newly happened during pregnancy or postpartally in pregnant women known with preeclampsia during pregnancy [1] [2].

Eclampsia is a strong cause of maternal deaths worldwide. Eclampsia is asso- 
ciated with approximately $13 \%$ of maternal deaths worldwide [2].

$\mathrm{MgSO}_{4}$ is the best drug used for reducing the incidence of eclampsia intrapartum and/or postpartum [3].

$\mathrm{MgSO}_{4}$ is the drug that the World Health Organization is recommending as the most effective, available and safe anticonvulsant treatment for severe pre-eclampsia and eclampsia [4].

There are two main courses available for $\mathrm{MgSO}_{4}$ treatment:

1) In the Pritchard Regimen, $4 \mathrm{~g}$ of $\mathrm{MgSO}_{4}$ is the starting loading dose, given slowly over 5 - 10 minutes intravenously followed by $10 \mathrm{~g}$ intramuscularly $(5 \mathrm{~g}$ in each gluteal muscle). Subsequently, then every 4 hours, $5 \mathrm{~g}$ is given intramuscularly into alternate gluteal muscle [5].

2) In the Zuspan regimen, $4 \mathrm{~g}$ is given slowly as the loading dose intravenously slowly over 5 - 10 min followed by $1-2 \mathrm{~g}$ infusion, the maintenance dose, every hour by an infusion pump [6].

About $40 \%$ of serum $\mathrm{MgSO}_{4}$ is bound to protein after its administration. The unbound $\mathrm{MgSO}_{4}$ ion diffuses into the different body tissue [5].

The clinical and toxicity effect of magnesium sulphate is correlated to its plasma concentration. 1.8 to $3.0 \mathrm{mmol} / \mathrm{L}$ plasma level of $\mathrm{MgSO}_{4}$ is the proper treatment of eclamptic fits. The dose of $\mathrm{MgSO}_{4}$ and its serum concentration for prophylaxis is not estimated [5].

The warning sign of impending $\mathrm{MgSO}_{4}$ toxicity in the mother firstly is loss of the patellar reflex with $\mathrm{MgSO}_{4}$ serum level between 3.5 and $5 \mathrm{mmol} / \mathrm{L}$ [5].

Magnesium sulphate toxicity is rare specially with close monitoring during treatment, but reducing the amount and duration of its treatment to reduce its adverse effects and reduce patient discomfort was the main concern of many researches [7].

In this study, comparison between the effectiveness of a shortened course of $\mathrm{MgSO}_{4}$ postpartally to the standard regimen in prevention of postpartal fits was done.

\section{Patients}

The study was applied on 40 cases of eclamptic mothers divided in two groups $\mathrm{A}$ and $B$ in which $A$ received standard regimen and $B$ received shortened regimen. Study was performed at Elshatby Maternity university hospital after approval of the ethics committee and signing the consent to be involved in this study. All the cases presented with history of preeclamptic toxemia or history of hypertension newly diagnosed in pregnancy came with eclamptic fits were included. Cases with history of recent epileptic fits, drug toxicity and chronic neurologic or psychological disease were excluded.

\section{Method}

Patients were divided into two groups, $\mathrm{A}$ and $\mathrm{B}$.

In the group $\mathrm{A}$, with standard course, $\mathrm{MgSO}_{4}$ loading dose of $4 \mathrm{~g}$ is given IV 
followed by $5 \mathrm{~g}$ IV every 4 hours as maintenance dose for 24 hours postpartally.

In the group $\mathrm{B}$, the loading dose is the same but the maintenance dose was limited to two doses of $5 \mathrm{~g} \mathrm{MgSO}_{4}$ given IV with 4 hours intervals postpartally or after the last eclamptic seizures.

In both regimens, $2 \mathrm{gm}$ of $\mathrm{MgSO}_{4}$ was given IV in cases of recurrence fit.

\section{Results}

Statistical analysis was done on 40 cases of eclamptic mothers divided in two groups A and B in which A received standard regimen and B received shortened regimen.

The recurrence of fits was not significantly different among the two groups $(\mathrm{p}=$ 0.229). In group $\mathrm{B}$, we found a significant reduction in the whole dose of $\mathrm{MgSO}_{4}$.

The fits recurrence, occurred in $15 \%$ in the $\mathrm{MgSO}_{4}$ short course group which was not significantly different from the $10 \%$ fits recurrence in the standard regimen group.

According to fits about $40 \%$ presented antepartum and $45 \%$ postpartum and the remaining (15\%) presented intrapartum the reduction in dose of $\mathrm{MgSO}_{4}$ in group B as short course $\mathrm{MgSO}_{4}$, the total dose of $\mathrm{MgSO}_{4}$ required was reduced to $14 \mathrm{~g}$ in $42.5 \%$ of the patients. This is more than $40 \%$ reduction in the whole dose of $\mathrm{MgSO}_{4}$ of $34-38 \mathrm{~g}$ required in $60 \%$ of the patients in the standard regimen.

Maternal outcomes were similar in the two groups as they have been followed for 6 weeks postpartally till they came for contraception counselling. The short course regimen got the benefit of low cost and less chance of drug toxicity without compromising quality of care (Table $1 \&$ Table 2 ).

\section{Discussion}

In our study, by reducing the duration of magnesium sulfate infusion, we have

Table 1. Comparison between the two studied groups according to fits.

\begin{tabular}{|c|c|c|c|c|c|c|}
\hline \multirow{2}{*}{ Fits } & \multicolumn{2}{|c|}{ Group A $(n=20)$} & \multicolumn{2}{|c|}{ Group B $(n=20)$} & \multirow{2}{*}{$x^{2}$} & \multirow{2}{*}{$\mathbf{P}$} \\
\hline & No. & $\%$ & No. & $\%$ & & \\
\hline \multicolumn{7}{|l|}{ Type } \\
\hline Antepartum & 8 & 40.0 & 10 & 50.0 & \multirow{3}{*}{0.576} & \multirow{3}{*}{${ }^{\mathrm{MC}} \mathrm{p}=0.829$} \\
\hline Intrapartum & 3 & 15.0 & 2 & 10.0 & & \\
\hline Postpartum & 9 & 45.0 & 8 & 40.0 & & \\
\hline \multicolumn{7}{|l|}{ Number } \\
\hline 1 & 15 & 75.0 & 16 & 80.0 & \multirow[b]{2}{*}{0.143} & \multirow{2}{*}{${ }^{\mathrm{FE}} \mathrm{p}=1.000$} \\
\hline 2 & 5 & 25.0 & 4 & 20.0 & & \\
\hline \multicolumn{7}{|l|}{ Recurrence } \\
\hline No & 18 & 90.0 & 17 & 85.0 & \multirow{2}{*}{0.229} & \multirow{2}{*}{${ }^{\mathrm{FE}} \mathrm{p}=1.000$} \\
\hline Yes & 2 & 10.0 & 3 & 15.0 & & \\
\hline
\end{tabular}

$\chi^{2}, \mathrm{p}: \chi^{2}$ and $\mathrm{p}$ values for Chi square test for comparing between the two groups. 
Table 2. Comparison between the two studied groups according to dose of magnesium sulphate $\left(\mathrm{MgSO}_{4}\right)$.

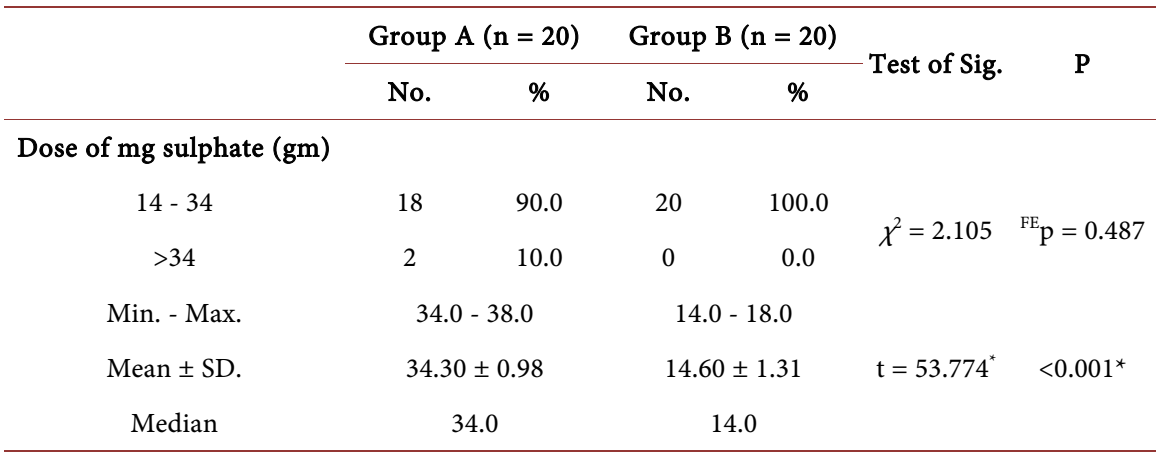

$\chi^{2}, \mathrm{p}: \chi^{2}$ and $\mathrm{p}$ values for Chi square test for comparing between the two groups; FE: Fisher Exact for Chi square test for comparing between group $\mathrm{A}$ and $\mathrm{B} ; \mathrm{t}, \mathrm{p}$ : $\mathrm{t}$ and $\mathrm{p}$ values for Student $\mathrm{t}$-test for comparing between the two groups; ${ }^{*}$ : Statistically significant at $\mathrm{p} \leq 0.05$.

achieved reduction in the $\mathrm{MgSO}_{4}$ whole dose, thereby safeguarding the patients against the untoward effects of $\mathrm{MgSO}_{4}$ toxicity.

About $40 \%$ presented antepartum and $45 \%$ postpartum and the remaining few (15\%) presented intrapartum, compared with Nigerian study done by Ado D. Geidamet al., [8] was $32 \%$ antepartum and $15 \%$ postpartum.

This comparative study supported that the short course $\mathrm{MgSO}_{4}$ is as effective as the standard regimen in the treatment of eclampsia.

This was explained by recurrence fits rate between two groups is nearly similar with using short course of $\mathrm{MgSO}_{4}$ as the same findings of Nigerian study done by Ado D. Geidam et al., [8] purposing to decrease risk of drug toxicity and drug cost [9].

\section{Conclusion}

$\mathrm{MgSO}_{4}$ short protocol treatment of eclamptic fits is as effective as the standard protocol of $\mathrm{MgSO}_{4}$ treatment.

\section{Acknowledgements}

The authors are thankful to the Obstetrics and Gynecology Department, Faculty of Medicine, Alexandria University.

\section{Compliance with Ethics Requirements}

All Institutional and National Guidelines for the care and use of animals (insects) were followed.

\section{Author Contributions}

DE designed the study and performed data collection and analysis. MR interpreted and supervised the Lab analysis results. NE and NH supervised the clinical examinations and US findings. DE wrote the manuscript. All authors were involved in the revision of the manuscript. 


\section{Conflicts of Interest}

The authors declare no conflicts of interest regarding the publication of this paper.

\section{References}

[1] Mattar, F. and Sibai, B.M. (2000) Eclampsia. VIII. Risk Factors for Maternal Morbidity. American Journal of Obstetrics and Gynecology, 182, 307-312. ttps://doi.org/10.1016/S0002-9378(00)70216-X

[2] Warrington, J.P. (2015) Placental Ischemia Increases Seizure Susceptibility and Cerebrospinal Fluid Cytokines. Physiological Reports, 3, e12634. https://doi.org/10.14814/phy2.12634

[3] Sibai, B.M. (1990) Eclampsia. VI. Maternal-Perinatal Outcome in 254 Consecutive Cases. American Journal of Obstetrics and Gynecology, 163, 1049-1054. https://doi.org/10.1016/0002-9378(90)91123-T

[4] Duley, L., Matar, H.E., Almerie, M.Q. and Hall, D.R. (2011) Alternative Magnesium Sulfate Regimens for Women with Pre-Eclampsia and Eclampsia: RHL Commentary. World Health Organization [WHO], Geneva.

[5] Flowers Jr., C.E., Easterling Jr., W.E., White, F.D., Jung, J.M. and Fox Jr., J.T. (1962) Magnesium Sulfate in Toxemia of Pregnancy. New Dosage Schedule Based on Body Weight. Obstetrics and Gynecology, 19, 315-327.

[6] Zuspan, F.P. (1978) Problems Encountered in the Treatment of Pregnancy-Induced Hypertension. A Point of View. American Journal of Obstetrics and Gynecology, 131, 591-597. https://doi.org/10.1016/0002-9378(78)90816-5

[7] Lakshmi, R., Upreti, D., Agrawal, A. and Raina, A. (2007) Late Postpartum Eclampsia at Five Weeks Post-Delivery. Singapore Medical Journal, 48, 946-947.

[8] Chama, C.M., Geidam, A.D., Bako, B., Mairiga, A.G. and Atterwahmie, A. (2013) A Shortened versus Standard Matched Postpartum Magnesium Sulphate Regimen in the Treatment of Eclampsia: A Randomised Controlled Trial. African Journal of Reproductive Health, 17, 131-136.

[9] Isler, C.M., Barrilleaux, P.S., Rinehart, B.K., Magann, E.F. and Martin Jr., J.N. (2003) Postpartum Seizure Prophylaxis: Using Maternal Clinical Parameters to Guide Therapy. Obstetrics and Gynecology, 101, 66-69.

https://doi.org/10.1097/00006250-200307000-00046 